\title{
Single Stage Reconstruction of Finger Gunshot Injury: A Case Report
}

\author{
Rahul Patil ${ }^{1} \quad$ Laxminarayan Bhandari $^{1}$ \\ ${ }^{1}$ Christine M Kleinert Institute of Hand and Microsurgery, Louisville, \\ Kentucky, United States
}

Indian J Plast Surg:2020;53:450-451

Gunshot injuries (GSI) produce complex wounds on fingers, involving segmental loss of multiple tissue layers and significant contamination. ${ }^{1}$ Such defects are challenging to reconstruct and achieve good functional outcome..$^{1-4}$ The traditional approach involves multistaged reconstruction that is fraught with significant delay, scarring and morbidity. ${ }^{1-4}$ The expected adhesions between tissue layers make a strong case for single-stage reconstruction followed by early mobilization. ${ }^{1-4}$

We report an 85-year-old gentleman who presented with an accidental GSI to his left ring finger, resulting in near total amputation at the proximal phalangeal level ( - Fig. 1 a). The ulnar neurovascular bundle was intact, perfusing the distal part. The X-ray revealed significant bone loss with severe comminution ( - Fig. $\mathbf{1} \mathbf{b}$ ). The patient requested all attempts be made to salvage the finger.

During exploration, we noted segmental loss of extensor tendon and radial neurovascular bundle. There was a soft-tissue defect over the dorsal and radial side of the proximal phalanx and metacarpophalangeal joint area. Both flexor tendons were intact. To maximize function and start

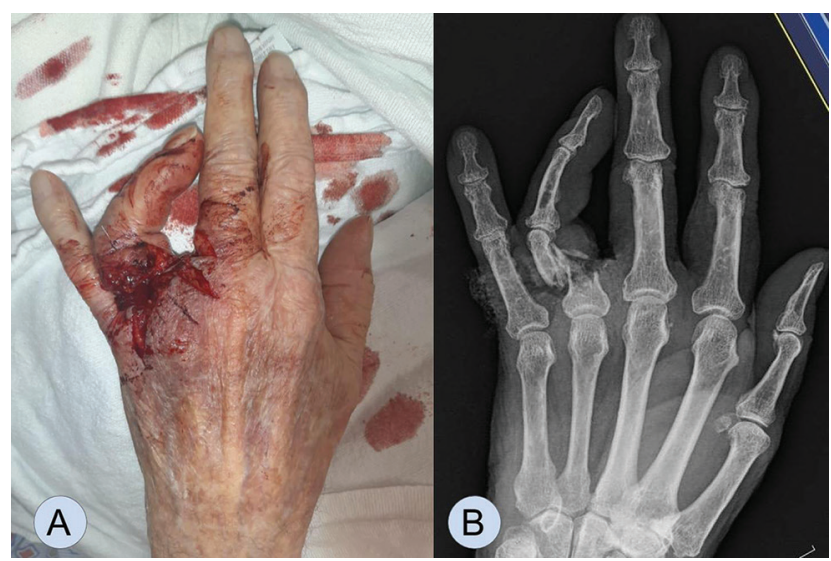

Fig. 1 (a) Gunshot wound of the left ring finger with wound on the dorsum of the hand. (b) X-ray image showing displaced comminuted fracture with bone loss.

published online

December 28, 2020
DOI https://doi.org/

10.1055/s-0040-1716308 ISSN 0970-0358.
Address for correspondence Laxminarayan Bhandari, MCh, Christine M Kleinert Institute of Hand and Microsurgery, 225 Abraham FLexner Way, Suite 750, Louisville, KY 40202, United States (e-mail: lax321@gmail.com).

early active motion, we decided to proceed with single stage reconstruction.

The skeletal defect was managed by acute shortening of the proximal phalanx, fixation with $0.8 \mathrm{~mm}$ plate and screw, and application of bone allograft ( - Fig. 2 a). Radial digital nerve was reconstructed with $2 \mathrm{~cm}$ long nerve allograft. Extensor tendon could be repaired primarily following a reduction in bone length. The resultant skin defect measured $5 \mathrm{~cm} \times$ $3.5 \mathrm{~cm}$ ( - Fig. 2 b). A free flow though the venous flap measuring $5 \times 3.5 \mathrm{~cm}$ was marked over two parallel veins on the volar forearm with a communication between them. The flap was raised suprafascially with adequate length of veins on both ends ( - Fig. 3a). The afferent radial-sided vein inflowing into the flap was connected to the proximal cut end of radial digital artery available in the wound. The outflow was channeled through the efferent ulnar-sided vein anastomosed to the dorsal hand vein ( $\mathbf{- F i g .} \mathbf{3} \mathbf{b}$ ). The patient was discharged on the first postoperative day without anticoagulants.

Early mobilization was started on postoperative day 3 . At 12 weeks, he had good range of motion of his hand, and total active motion of the injured finger was 140 degrees.

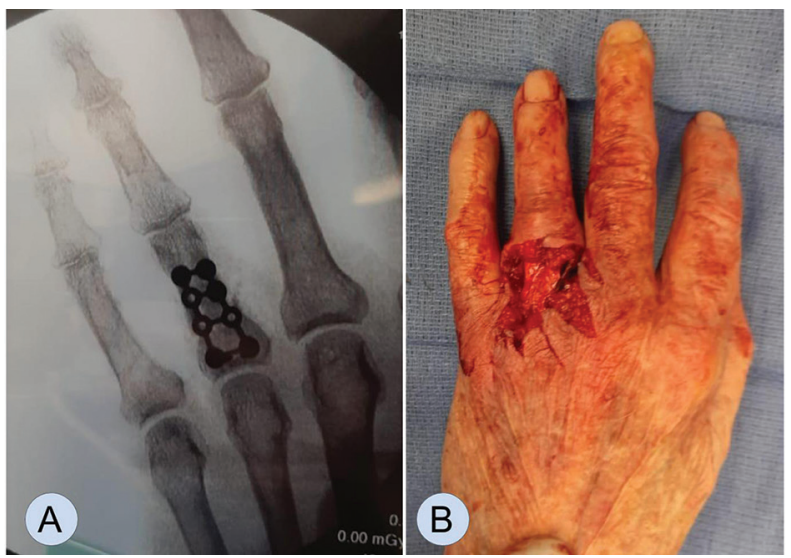

Fig. 2 (a) Following shortening and bone fixation with plate and screws. (b) The resultant defect measured $3.5 \mathrm{~cm}$ long and $5 \mathrm{~cm}$ wide.

(C2020. Association of Plastic Surgeons of India.

This is an open access article published by Thieme under the terms of the Creative Commons Attribution-NonDerivative-NonCommercial-License, permitting copying and reproduction so long as the original work is given appropriate credit. Contents may not be used for commercial purposes, or adapted, remixed, transformed or built upon. (https://creativecommons.org/licenses/by-nc-nd/4.0/).

Thieme Medical and Scientific Publishers Pvt. Ltd. A-12, 2nd Floor, Sector 2, Noida-201301 UP, India 


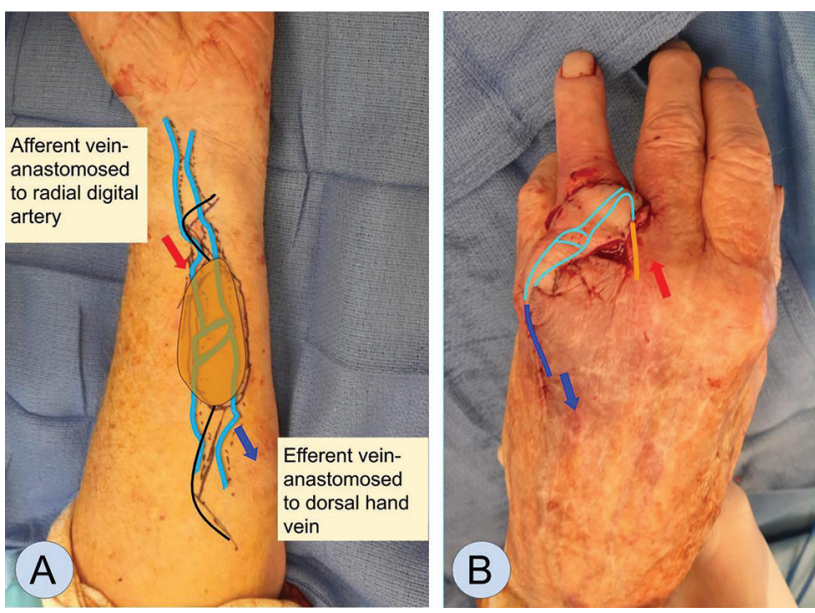

Fig. 3 (a) Free venous flow through flap was designed on the volar forearm over two parallel veins with communication. The radial afferent vein was selected as inflow for the flap by anastomosing it with the severed radial digital artery. The ulnar efferent vein was selected as the draining vein and anastomosed to the dorsal hand vein. (b) Flap after anastomosis.

Palm to pulp distance was $1 \mathrm{~cm}$, and there was approximately 20 degrees of extensor lag at the proximal interphalangeal (PIP) joint. His other digits had a full range of motion.

\section{(-Fig. 4; Video 1).}

GSI of fingers often produce segmental defects in multiple tissue planes. Such complex injuries in elderly patients, single-digit involvement at flexor zone 2 , are relative indications for amputation. Getting rid of problem digit and preserving function of intact digits takes priority in such situations. ${ }^{5}$ However, not all patients are keen on amputation. Retained vascularity, sensation and tendon function can make the patient reluctant for amputation. The challenge for the surgeon is to ensure there would be no further loss of function of other digits due to reconstructive attempt. To achieve these objectives, initiation of early active motion is paramount. The prerequisites for early active motion include a stable bone fixation, nerve repair without tension, strong tendon repair, and supple skin coverage. We achieved these objectives by utilizing a very low-profile $0.8 \mathrm{~mm}$ plate, bone allograft, nerve allograft, and venous flow through flap. ${ }^{6}$

Traditional reconstruction in such cases would be multistaged, involving an external fixator to stabilize the skeleton, followed by soft-tissue cover. Subsequently, bone grafting and tendon reconstruction would be performed..$^{1,2}$ Often, an additional stage of tenolysis may be needed. ${ }^{2} \mathrm{~A}$ single stage reconstruction has the benefit of starting early active motion as well as achieving maximal function with minimal morbidity. This also limits potential stiffness of other fingers.

\section{Financial Disclosure}

Nil.

\section{Conflicts of Interest}

None declared.

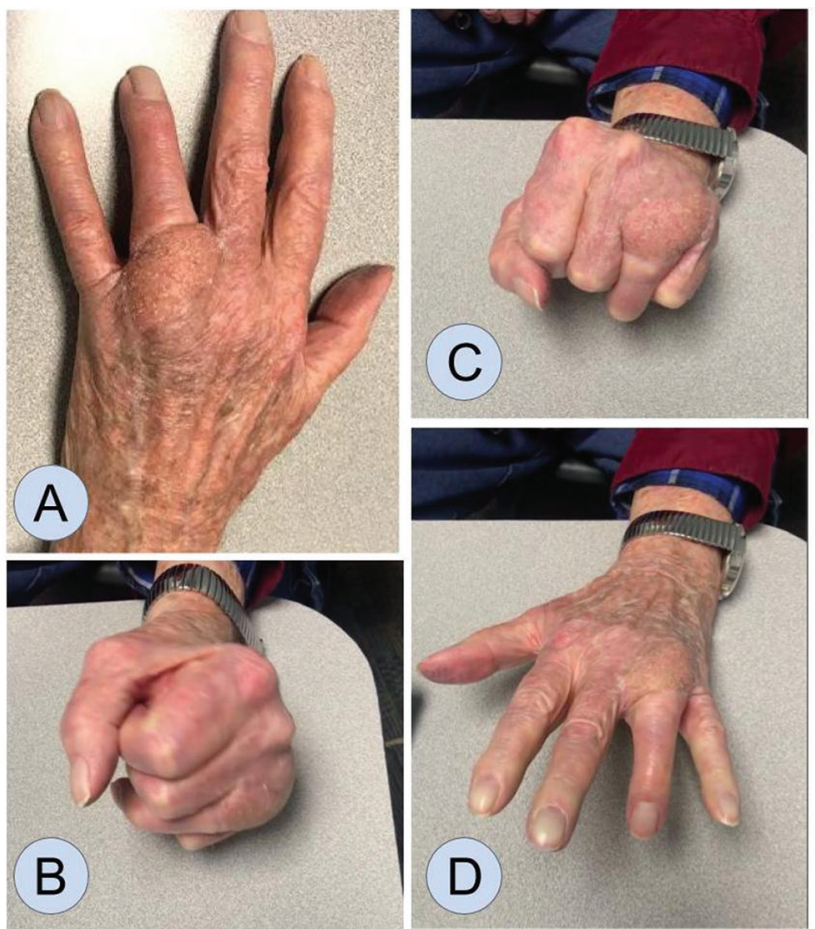

Fig. 412 weeks postoperative results showing (a) settled flap. (b, c, d) range of motion.

\section{Video 1 \\ Showing function at 3 months follow-up. Online content includ- ing video sequences viewable at: https://www. thieme-con- nect.com/products/ejournals/html/ 10.1055/s-0040-1716308}

\section{Acknowledgment}

Nil.

\section{References}

1 Germann G, Karle B, Brüner S, Menke H. [Treatment strategy in complex hand injuries]. Unfallchirurg 2000;103(5):342-347

2 Lin CH, Wei FC, Lin YT, Chen CT. Composite palmaris longusvenous flap for simultaneous reconstruction of extensor tendon and dorsal surface defects of the hand-long-term functional result. J Trauma 2004;56(5):1118-1122

3 Sundine M, Scheker LR. A comparison of immediate and staged reconstruction of the dorsum of the hand. J Hand Surg $[\mathrm{Br}]$ 1996;21(2):216-221

4 Koul AR, Patil RK, Philip V. Complex extensor tendon injuries: early active motion following single-stage reconstruction. J Hand Surg Eur Vol 2008;33(6):753-759

5 Maricevich M, Carlsen B, Mardini S, Moran S. Upper extremity and digital replantation. Hand (N Y) 2011;6(4):356-363

6 Tasi TM, Tien HY. Flow through and arterialized venous flaps in surgery of the hand local flap coverage about the hand. Atlas Hand Clin 1998;3(2):163-177 